\title{
UM NOVO MODELO DE EJA PARA O ENSINO MÉDIO NO RIO DE JANEIRO
}

\author{
ÂNGELO DAMACENO HOTTZ' \\ CLÉCIO DA SILVA FERREIRA" \\ LEONARDO OSTWALD VILARDI"'
}

I Secretaria Estadual de Educação do Rio de Janeiro, Rio de Janeiro-RJ, Brasil; http://orcid.org/0000-00019290-8144; hottz.angelo@gmail.com

II Universidade Federal de Juiz de Fora (UFJF), Juiz de Fora-MG, Brasil; http:// orcid.org/0000-0002-7820-1350: clecio.ferreira@yahoo.com.br

III Pontifícia Universidade Católica do Rio de Janeiro (PUC-Rio), Rio de Janeiro-RJ; Universidade Federal de Juiz de Fora (UFJF), Juiz de Fora-MG,

Brasil; http://orcid.org/O000-00031098-0551; leonardo.vilardi@caed.ufjf.br

\section{RESUMO}

O presente artigo analisa os resultados de uma modalidade de ensino voltada para alunos que, na idade oportuna, não puderam cursar a educação básica. Hoje a Educação de Jovens e Adultos (EJA) atende, inclusive, o ensino médio. A Secretaria de Estado de Educação do Rio de Janeiro (Seeduc-RJ), até 2013, ofertava o ensino médio na modalidade EJA em três fases semestrais e, somente a partir desse mesmo ano, tendo observado os desempenhos insuficientes da fase III no Sistema de Avaliação da Educação do Estado do Rio de Janeiro (Saerj), foi introduzida na rede de ensino uma nova proposta de oferta de EJA em quatro módulos, também semestrais. Este artigo analisa os resultados do Saerj mensurando o quanto esse novo desenho de EJA, em seu primeiro ciclo, do módulo I ao módulo IV, foi capaz de elevar a proficiência média em Língua Portuguesa e Matemática, estimada para os concluintes do módulo IV, em relação à proficiência média dos concluintes da fase III, estimada em anos anteriores a 2014.

\footnotetext{
PALAVRAS-CHAVE AVALIAÇÃO DA EDUCAÇÃO - PROFICIÊNCIA • EDUCAÇÃO DE JOVENS E ADULTOS (EJA) • SISTEMA DE AVALIAÇÃO DA EDUCAÇÃO DO ESTADO DO RIO DE JANEIRO (SAERJ).
} 


\section{UN NUEVO MODELO DE EJA PARA LA EDUCACIÓN MEDIA EN RIO DE JANEIRO}

RESUMEN

El presente artículo analiza los resultados de una modalidad de enseñanza destinada a alumnos que, en la edad oportuna, no pudieron frecuentar la educación básica. En la actualidad la Educación de Jóvenes y Adultos (EJA) atiende incluso la educación media. Hasta el 2013, la Secretaría de Estado de Educación de Rio de Janeiro (Seeduc-RJ), ofertaba la educación media en la modalidad EJA en tres fases semestrales y tan solo desde este mismo año, habiendo observado los desempeños insuficientes de la fase III en el Sistema de Evaluación de la Educación del Estado de Rio de Janeiro (Saerj), se introdujo en la red de enseñanza una nueva propuesta de oferta de EJA en cuatro módulos, también semestrales. Este artículo analiza los resultados de Saerj al medir cuánto este nuevo diseño de EJA, en su primer ciclo, del módulo I al IV, fue capaz de elevar la competencia media en Idioma Portugués y Matemáticas, estimada para los concluyentes del módulo IV, en relación a la competencia media de los concluyentes de la fase III, estimadas en años anteriores al 2014.

palabras clave eVALUACIÓN dE LA EDUCACIÓN • COMPETENCIA • EDUCAÇÃO DE JOVENS E ADULTOS (EJA) • SISTEMA DE AVALIAÇÃO DA EDUCAÇÃO DO ESTADO DO RIO DE JANEIRO (SAERJ).

\section{A NEW MODEL OF EJA FOR HIGH SCHOOL IN RIO DE JANEIRO}

ABSTRACT

The present article analyzes the results of a teaching modality directed at students who, at the appropriate age, could not attend Basic Education. Today, Educação de Jovens e Adultos (EJA [Youth and Adult Educaction]) also includes High School. The State Department of Education of Rio de Janeiro (Seeduc-RJ), until 2013, provided High School YAE in threesemester phases. In that same year, by analyzing the inadequate performance of phase III in the State Education Assessment System in Rio de Janeiro (Saerj), a new YAE proposal was introduced into the Education System in four biannual modules. The present article offers a analysis of the Saerj results by measuring how much this new YAE design, in its first cycle from modules I to IV, raised the average proficiency in the Portuguese Language and Mathematics estimated for the graduates of module IV, in relation to the average proficiency of the graduates of phase III, estimated in the years prior to 2014.

KEYWORDS EDUCATION EVALUATION • PROFICIENCY • EDUCAÇÃO DE JOVENS E ADULTOS (EJA) • SISTEMA DE AVALIAÇÃO DA EDUCAÇÃO DO ESTADO DO RIO DE JANEIRO (SAERJ). 


\section{INTRODUÇÃO}

A partir de 2011, houve uma grande reformulação do planejamento estratégico que impactou diretamente na gestão de toda a rede de ensino estadual do Rio de Janeiro. Esse planejamento foi ponto de partida para que houvesse melhora de indicadores que refletem realidades, tais como distorção idade-série, rendimento e aprendizagem. O ensino médio (EM), modalidade Educação de Jovens e Adultos (EJA), também foi alvo de inovações quando, em 2013, iniciou-se a transição da EJA em três fases semestrais para EJA em quatro módulos semestrais. Essa última, por se diferenciar em vários aspectos da primeira, foi denominada inicialmente de Nova EJA, ${ }^{1}$ até que se finalizou por completo a transição para a nova proposta.

A análise dos resultados do primeiro ciclo da Nova EJA, iniciado no primeiro semestre de 2013 com término no segundo semestre de 2014, será o foco principal de discussão deste artigo, visto que a EJA, enquanto modalidade de ensino alternativa, pensada para jovens e adultos que não tiveram a oportunidade de escolarizar-se em idade própria, está am- 
parada pela legislação educacional brasileira, contudo, ainda não é alvo do Sistema de Avaliação da Educação Básica (Saeb) de âmbito nacional, embora seja uma forma de oferta da educação básica.

A Secretaria de Estado de Educação do Rio de Janeiro (Seeduc-RJ) avaliou, até 2015, os alunos de EJA no momento da conclusão do ensino médio, por meio do Sistema de Avaliação da Educação do Estado do Rio de Janeiro (Saerj²). Sendo observados os desempenhos insuficientes para EJA organizada em fases e os índices elevados de distorção idade-série no ensino regular, essa modalidade de ensino foi reformulada com ênfase em material didático apropriado preparado para uma clientela com anseios e características específicas. As edições anuais do Saerj são pontos-chave para as análises desenvolvidas ao longo deste texto por dar subsídios ao objetivo de identificar o quanto a Nova EJA superou a anterior em níveis de proficiências estimadas para os alunos concluintes.

$\mathrm{O}$ artigo está organizado em cinco seções. A primeira faz uma breve descrição sobre o panorama da EJA no Brasil. A seguir são abordadas algumas estatísticas relacionadas ao ingresso e à permanência dos alunos na EJA, logo depois apresenta-se a metodologia empregada ao estudo.

Na quarta seção, discutem-se os resultados do Saerjinho ${ }^{3}$ e Saerj, ancorando-se em análises estatísticas que buscam respostas para o problema levantado. As análises estão voltadas para os resultados de proficiência em Língua Portuguesa e Matemática. Primeiramente, um estudo longitudinal, com base na proficiência aferida no início do curso do ensino médio e na sua conclusão, é apresentado para entender em até que medida houve ganhos significativos para os alunos concluintes do primeiro ciclo de EJA, iniciado no primeiro semestre de 2013. Na sequência, são analisados os resultados de quatro edições do Saerj, de 2011 a 2014, modalidade regular e EJA, para elucidar como os resultados responderam ao movimento de transição da EJA em fases para EJA em módulos.

Por fim, o artigo é concluído com a reflexão acerca de ações que possam empreender esforços para melhorias constantes na qualidade da educação ofertada a um público com características tão particulares.
2 O Saerj foi um sistema de avaliação que, até 2015, avaliou os alunos da rede estadual de ensino do Rio de Janeiro por meio de testes de Língua Portuguesa e Matemática, na conclusão do $1^{\circ}$ segmento do ensino fundamental (EF), $2^{\circ}$ segmento do EF e ensino médio.

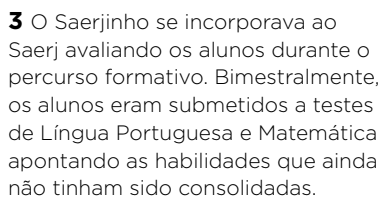

3 O Saerjinho se incorporava ao Saerj avaliando os alunos durante o percurso formativo. Bimestralmente, os alunos eram submetidos a testes de Língua Portuguesa e Matemática apontando as habilidades que ainda não tinham sido consolidadas. 


\section{DO DIREITO À EDUCAÇÃO À EDUCAÇÃO DE JOVENS E ADULTOS}

Historicamente, ao retrocedermos aos caminhos percorridos até a conquista do direito à educação no Brasil, com acesso universalizado às escolas, encontramos os movimentos sociais, as influências de órgãos internacionais, os pequenos avanços nos textos legais no que diz respeito à execução plena desse direito no cotidiano das camadas populares menos favorecidas e, principalmente, as reformas educativas com vistas a atender às diversas classes sociais demandantes dos serviços educacionais, assim como os variados perfis de alunos a quem esse direito se destina (BROOKE, 2012).

No que se refere aos movimentos sociais, o Parecer n. 11/2000 do Conselho Nacional de Educação (CNE) traz algumas considerações que nos auxiliam a entendê-los não somente como manifestos ou reivindicações por direitos não concretizados, mas também como algo sistemático que se observava desde o fim do século XIX e início do XX. O documento disserta sobre "a tradição de movimentos sociais organizados, via associações sem fins lucrativos” (BRASIL, 2000, p. 15) para oferecer a instrução primária logo no início do Brasil República. Tal movimento tinha, por vezes, a intenção de atender a demandas específicas, "eram iniciativas autônomas de grupos, clubes e associações que almejavam, de um lado, recrutar futuros eleitores e de outro atender demandas específicas" (BRASIL, 2000, p. 15), diante da ausência do poder público no assunto.

Dada a intensidade maior desses movimentos civis em algumas regiões do país em detrimento de outras e pelo fato de o Brasil ser formado por regiões geográficas com diferenças sociais, econômicas e culturais marcantes, o processo de escolarização da população não se deu de forma homogênea em todos os estados brasileiros. Logo após o fim da Ditadura Militar, em março de 1985 o processo de redemocratização do país foi um marco importante para a ascensão do acesso à educação brasileira pelos mais pobres, visto que, para um país prosperar em um regime democrático, há de se consolidar um povo instruído, capaz de promover debates e organizar-se enquanto cidadãos. Sob essa perspectiva, 
[...] o direito à educação, assim entendido, tem existido como fundamento à ideia de educação como condição necessária, ainda que não suficiente, para se pensar o modelo democrático de sociedade, no qual o papel do Estado, como garantidor desse direito, tem sido insubstituível. (PAIVA, 2005, p. 152)

Foram várias as tentativas de adequar à oferta do ensino as diferentes realidades que segregam, ainda, a população deste país. Dentre essas, vale lembrar o Movimento Brasileiro de Alfabetização (Mobral), de 1967, e os Centros Integrados de Educação Pública (Ciep), implantados de 1981 a 1994 na rede estadual de ensino do Rio de Janeiro.

No que tange à EJA, política direcionada àqueles "que não tiveram uma adequada correlação idade/ano escolar em seu itinerário educacional e nem a possibilidade de prosseguimento de estudos" (BRASIL, 2000, p. 9), houve um movimento consensual e gradativo de que essa modalidade não poderia restringir-se a somente alfabetizar jovens e adultos nos princípios mais básicos do letramento em Língua Portuguesa e Matemática. É o que explica Paiva (2005):

No atual momento político, depois de passar um ano no embate da prioridade para a alfabetização de adultos, defendida pelo MEC x continuidade da EJA, bandeira antiga dos educadores e dos Fóruns, o governo brasileiro reconhece o movimento histórico nacional e internacional de luta em defesa do direito à educação para todos [...]. A partir de 2004 investe no alargamento político da EJA, entendendo que um programa de alfabetização, sem garantir o direito à continuidade, é pouco para fazer justiça social a tantos excluídos do direito à educação. Assim, estabeleceu que a continuidade de estudos é meta inalienável da EJA, que também se põe, como desafio, a garantia do acesso ao Ensino Médio, por via da mesma modalidade. (PAIVA, 2005, p. 201)

A autora argumenta que a universalização do ensino, enquanto afirmação da garantia de um direito subjetivo a todos com idade própria para matricularem-se em classes 
de ensino regular da educação básica, deve se estender, inclusive, àqueles que sofreram privação do ensino público, acarretando-lhes prejuízos formativos pela falta de escolas e oportunidades de escolarização na época apropriada. Esse novo cenário se insere na agenda dos governos federal, estaduais e municipais.

Ainda sobre o Parecer n. 11/2000 do CNE, além de detalhar todo o caminho político e histórico percorrido até a atual consolidação da EJA em todas as etapas da educação básica, o documento reafirma a importância dessa modalidade enquanto assunto inerente ao Plano Nacional de Educação, na época, tramitando no Congresso Nacional.

Os déficits do atendimento no Ensino Fundamental resultaram, ao longo dos anos, num grande número de jovens e adultos que não tiveram acesso ou não lograram terminar o ensino fundamental obrigatório. Embora tenha havido progresso com relação a esta questão, o número de analfabetos é ainda excessivo e envergonha o país. [...] todos indicadores apontam para a profunda desigualdade regional na oferta de oportunidades educacionais e a concentração de população analfabeta ou insuficientemente escolarizada nos bolsões de pobreza existente no país. (BRASIL, 2000, p. 47)

Hoje, esse déficit educacional, embora menor, porém existente, é alvo de políticas públicas cada vez mais numerosas, com vistas a colocar o $1^{\circ}$ segmento do ensino fundamental regular no mesmo patamar dos países desenvolvidos até 2022, quando o país completará o bicentenário da independência. Neste ano, espera-se que o Índice de Desenvolvimento da Educação Básica (Ideb) para essa primeira etapa da educação básica alcance 6,0 - índice de qualidade equivalente ao dos sistemas educacionais dos países desenvolvidos. Para os anos finais do ensino fundamental regular, segunda etapa da educação básica, essa meta de 6,0 é prevista para 2026, quatro anos depois que o $1^{\circ}$ segmento atingir o nível de excelência esperado. Só em 2029 o ensino médio regular deverá alcançar o Ideb 6,0 para que, dessa forma, tenha-se finalizado o esforço nacional para elevar a 
qualidade do ensino brasileiro ao mesmo nível dos países membros da Organização para a Cooperação e Desenvolvimento Econômico (OCDE).

Tais esforços estão amparados por metas de Ideb bianuais, calculadas pelo Instituto Nacional de Estudos e Pesquisas Educacionais Anísio Teixeira (Inep), para escolas, sistemas de ensino, unidades da federação e nação. Até então, o Saeb não abarca a EJA. Contudo, mesmo sabendo da importância de o país mobilizar recursos para garantir a qualidade da educação das gerações atuais, que se encontram na idade adequada para os anos do ensino fundamental e séries do ensino médio, em curso regular, se faz necessário oferecer uma modalidade de ensino alternativa, sendo essa na modalidade EJA, que possa colocar os egressos do ensino regular e da EJA em igualdade de condições para adentrar em universidades públicas ou concorrer a vagas no mercado de trabalho.

Para garantir uma educação de qualidade na modalidade EJA, a Seeduc repensou a forma de ofertá-la e incorporou seus alunos no Saerjinho para fins de monitoramento e acompanhamento do desempenho desses estudantes nas competências e habilidades propostas pelo currículo de cada um dos quatro módulos do curso, ou seja, no percurso formativo. Embora os concluintes dessa modalidade tenham sido submetidos ao Saerj desde sua implementação, o ano de 2013 marcou a avaliação bimestral dos resultados de alunos da EJA, com foco maior no desenho modular.

Uma política pública emerge da necessidade de promover ações corretivas e interferências imediatas no meio social. Cidadãos que não concluíram seus estudos em idade própria ou que, por algum motivo, o abandonaram não podendo frequentar salas de aula de ensino regular configuram um problema de ordem pública e, por isso, requerem interferência prioritária por parte dos governos. Embora a Lei de Diretrizes e Bases (LDB) da Educação Nacional de 1996 tenha se preocupado em mencionar enfaticamente em seu texto a relevância da EJA, cabe ao Poder Executivo e aos Conselhos de Educação deliberar de que forma se dará a oferta dessa modalidade à população (BRASIL, 1996). Em 26 de agosto de 2003, ficou instituída a EJA para o ensino 
médio por meio da deliberação CEE n. 285. O Art. $1^{\circ}$ desse documento menciona que

Os cursos de Educação de Jovens e Adultos autorizados pelo Órgão competente do Poder Público Estadual e oferecidos por instituições de ensino privadas ou públicas que não integrantes da Administração Pública Direta do Estado e dos Municípios, devidamente credenciadas, qualquer que seja a metodologia aplicada, não terão duração inferior a 24 (vinte e quatro) meses, quando se tratar de ensino correspondente às quatro últimas séries do Ensino Fundamental, nem inferior a 18 (dezoito) meses, quando em nível equivalente ao Ensino Médio. (RIO DE JANEIRO, 2003)

Com base nesse texto, ao oferecer o ensino médio na modalidade EJA, a Seeduc organizou essa etapa de escolaridade em três fases semestrais. A similaridade existente entre essa configuração de EJA e as séries anuais do ensino médio oferecido em horário parcial no estado do Rio de Janeiro se concretiza na medida em que as disciplinas e conteúdos propostos para o ensino médio regular eram os mesmos trabalhados nas três fases da EJA. Contrapondo essa estrutura de oferta, em 2012 instituiu-se a Nova EJA, por meio do Parecer 091.

Para efetiva implementação desta política foi construída uma metodologia completa, composta dos seguintes elementos: 1 - Matriz curricular específica; 2 - Formação de professores da EJA; 3 - Material Didático impresso do aluno; 4 - Material do professor; 5 - Processo de avaliação de estudo; 6 - EJA virtual. Todos elementos estão concatenados temporalmente, tendo como base a matriz curricular. A matriz curricular de referência está estruturada em 4 módulos [...] A estrutura organizacional das disciplinas da área de Ciência Humanas (Língua Estrangeira, História, Geografia, Artes, Filosofia e Sociologia) e as da área de Ciências da Natureza (Biologia, Química, Física e Educação Física) estão distribuídas em períodos alternados, o que não se aplica às disciplinas de Matemática e Língua Portuguesa, presentes nos 4 módulos. (RIO DE JANEIRO, 2012, p. 48) 
Essa reforma curricular e organizacional pensada para tal modalidade de ensino mobilizou a Subsecretaria de Gestão de Ensino (Sugen) num propósito único: assegurar a continuidade dos estudos para jovens e adultos, concluintes do ensino fundamental, sem prejuízos de aprendizagem. Nesse contexto têm-se, então, três realidades objeto de análise. A primeira corresponde aos resultados do ensino médio regular que servirão de parâmetro comparativo para os resultados da EJA em módulos. A segunda são os resultados da EJA organizada em fases, não mais existente na rede de ensino estadual do Rio de Janeiro e com média das proficiências dos alunos inferior aos do ensino médio regular, que representam uma realidade da qual a rede espera distanciamento por meio da nova política para essa modalidade de ensino. Por fim, os resultados da EJA em módulos no Saerj de 2014, cujo objetivo é apurar o desempenho dos primeiros concluintes desse novo desenho, confrontando com as duas primeiras realidades - EJA em fases, da qual se espera um afastamento, e ensino médio regular, em que é esperada uma aproximação.

Assim como o desempenho, antes de apresentar as análises de proficiência, é importante discutir alguns números que também se configuram em problemas para EJA, tais como ingresso e permanência desse público nas salas de aula.

\section{EJA EM NÚMEROS}

Considerando-se a universalização do ensino fundamental e os esforços para manter os jovens com idade escolar na educação básica, ensino regular, a EJA assume um percentual de matrículas bem inferior. Contudo, tanto o número quanto o percentual de alunos no estado do Rio de Janeiro sofreram redução nos últimos anos. A Tabela 1 mostra um recuo considerável nas matrículas de 2015 em relação a 2009. 
TABELA 1 - Matrículas no ensino médio regular e EJA, presencial e semipresencial, no estado do Rio de Janeiro

\begin{tabular}{c|l|c|c|c|c|c|c|c|c}
\hline \multirow{2}{*}{ ENSINO MÉDIO } & \multicolumn{2}{c|}{2009} & \multicolumn{2}{c|}{2011} & \multicolumn{2}{c|}{2013} & \multicolumn{2}{c}{2015} \\
\cline { 3 - 10 } \multicolumn{2}{c|}{} & $\mathbf{N}$ & $\%$ & $\mathbf{N}$ & $\%$ & $\mathbf{N}$ & $\%$ & $\mathbf{N}$ & $\%$ \\
\hline \multirow{4}{*}{ Regular } & Propedêutico & 579.644 & 70,6 & 563.412 & 76,2 & 553.260 & 78,5 & 534.591 & 77,2 \\
\cline { 2 - 10 } & Normal & 40.391 & 4,9 & 32.374 & 4,4 & 22.130 & 3,1 & 20.199 & 2,9 \\
\cline { 2 - 10 } & Integrado & 15.383 & 1,9 & 13.894 & 1,9 & 21.356 & 3,0 & 28.261 & 4,1 \\
\hline \multirow{2}{*}{ EJA } & $\begin{array}{l}\text { Presencial e } \\
\text { semipresencial }\end{array}$ & 185.649 & 22,6 & 129.225 & 17,5 & 107.676 & 15,3 & 109.408 & 15,8 \\
\hline & Total & 821.067 & 100,0 & 738.905 & 100,0 & 704.422 & 100,0 & 692.459 & 100,0 \\
\hline
\end{tabular}

Fonte: Elaboração dos autores com base nos dados disponíveis no site do Inep.

Em 2015, a redução das matrículas em relação a 2009 chegou a $41,1 \%$ no estado fluminense. Comparado ao cenário brasileiro, que sofreu um declínio de 17,9\% (de 1.547.275 para 1.270.198 matrículas), o decréscimo no Rio de Janeiro registrado pelo Inep aponta para um evento que merece atenção. Jaqueline Ventura (2016), doutora em Educação e professora da Faculdade de Educação da Universidade Federal Fluminense, defende que

\section{[...] esse dramático quadro de redução não se justifica pois tínhamos uma elevada demanda potencial em 2010 Os dados oficiais traçam um cenário preocupante: não se constituíram políticas públicas que garantam o direito à escolarização, visto ser evidente que a oferta de EJA está muito aquém das necessidades da população.}

Por outro lado, a política de reformulação da oferta de EJA no estado do Rio de Janeiro foi uma iniciativa da Secretaria de Estado de Educação para garantir políticas públicas que assegurem o direito à escolarização para a demanda por EJA no estado. Apesar de o número de matrículas ter sofrido redução significativa, segundo a Superintendência de Planejamento e Integração da Redes (Suplan) da Seeduc, há um número expressivo de vagas de EJA ofertadas e não preenchidas desde a implementação dessa nova proposta.

Dentre os problemas que envolvem a EJA no estado do Rio de Janeiro, a redução significativa no número de matrículas fica em segundo plano em face dos índices de reprovação e abandono nessa modalidade de ensino. Embora o Inep não divulgue estatísticas de rendimento para EJA, 
disponibilizando índices de reprovação, aprovação e abandono somente para o ensino regular, as Tabelas 2 e 3 apresentam taxas de rendimento da EJA em fases e EJA em módulos no período de 2011 a 2014.

TABELA 2 - Taxas de rendimento para EJA organizada em três fases semestrais

\begin{tabular}{c|l|c|c|c|c|c}
\hline \multicolumn{2}{c|}{} & $\begin{array}{c}\mathbf{2} \text { SEM. } \\
\mathbf{2 0 1 1}\end{array}$ & $\begin{array}{c}\mathbf{1} \text { SEM. } \\
\mathbf{2 0 1 2}\end{array}$ & $\begin{array}{c}\mathbf{2} \text { SEM. } \\
\mathbf{2 0 1 2}\end{array}$ & $\begin{array}{c}\mathbf{1} \text { SEM. } \\
\mathbf{2 0 1 3}\end{array}$ & $\begin{array}{c}\mathbf{2} \text { SEM. } \\
\mathbf{2 0 1 3}\end{array}$ \\
\hline \multirow{4}{*}{ FASE I } & Abandono / Repetência por frequência & $39,2 \%$ & $40,2 \%$ & $38,0 \%$ & - & - \\
\cline { 2 - 7 } & Aprovados & $41,8 \%$ & $48,4 \%$ & $56,0 \%$ & - & - \\
\cline { 2 - 7 } & Repetência por nota & $19,0 \%$ & $11,3 \%$ & $6,0 \%$ & - & - \\
\hline \multirow{3}{*}{ FASE II } & Abandono / Repetência por frequência & $26,8 \%$ & $28,1 \%$ & $24,9 \%$ & $23,4 \%$ & - \\
\cline { 2 - 7 } & Aprovados & $56,1 \%$ & $61,2 \%$ & $70,4 \%$ & $70,4 \%$ & - \\
\cline { 2 - 7 } & Repetência por nota & $17,0 \%$ & $10,8 \%$ & $4,6 \%$ & $6,3 \%$ & - \\
\hline \multirow{3}{*}{ FASE III } & Abandono / Repetência por frequência & $19,0 \%$ & $20,1 \%$ & $16,5 \%$ & $14,4 \%$ & $7,5 \%$ \\
\cline { 2 - 7 } & Aprovados & $68,0 \%$ & $75,0 \%$ & $80,4 \%$ & $82,5 \%$ & $91,5 \%$ \\
\cline { 2 - 7 } & Repetência por nota & $13,1 \%$ & $4,9 \%$ & $3,1 \%$ & $3,1 \%$ & $1,0 \%$ \\
\hline
\end{tabular}

Fonte: Elaboração dos autores com base nos dados disponibilizados pela Seeduc-RJ.

O problema se destaca na medida em que as taxas de abandono e reprovação por frequência são expressivas. Abandono e reprovação por frequência estão representados em um único percentual, visto que ambas as situações finais podem, muitas vezes, representar uma mesma realidade. $\mathrm{O}$ aluno reprovado por frequência, conforme base de dados recebida para análise, na maioria dos casos, não apresentou nota suficiente para aprovação e, ao mesmo tempo, número expressivo de faltas, configurando-se numa perspectiva muito próxima à do abandono. No decorrer das três fases semestrais, observaram-se, gradativamente, uma diminuição das taxas de abandono e reprovação e, em contrapartida, aumento das taxas de aprovação. A mesma realidade pode ser verificada no formato de EJA em quatro módulos semestrais, conforme mostra a Tabela 3. 
TABELA 3 - Taxas de rendimento para EJA organizada em quatro módulos semestrais

\begin{tabular}{|c|c|c|c|c|c|}
\hline & & $\begin{array}{c}10 \text { SEM. } \\
2013\end{array}$ & $\begin{array}{c}2 \text { o SEM. } \\
2013\end{array}$ & $\begin{array}{c}1 \% \text { SEM. } \\
2014\end{array}$ & $\begin{array}{c}2 \circ \text { SEM. } \\
2014\end{array}$ \\
\hline \multirow{3}{*}{ MÓDULO 1} & Abandono / Repetência por frequência & $33,2 \%$ & $40,6 \%$ & $35,2 \%$ & $41,5 \%$ \\
\hline & Aprovados & $61,5 \%$ & $51,7 \%$ & $59,3 \%$ & $52,4 \%$ \\
\hline & Repetência por nota & $5,3 \%$ & $7,7 \%$ & $5,5 \%$ & $6,1 \%$ \\
\hline \multirow{3}{*}{ MÓDULO 2} & Abandono / Repetência por frequência & - & $24,5 \%$ & $31,2 \%$ & $29,4 \%$ \\
\hline & Aprovados & - & $69,5 \%$ & $63,5 \%$ & $66,0 \%$ \\
\hline & Repetência por nota & - & $6,0 \%$ & $5,4 \%$ & $4,6 \%$ \\
\hline \multirow{3}{*}{ MÓDULO 3} & Abandono / Repetência por frequência & - & - & $15,5 \%$ & $24,3 \%$ \\
\hline & Aprovados & - & - & $81,2 \%$ & $70,5 \%$ \\
\hline & Repetência por nota & - & - & $3,3 \%$ & $5,2 \%$ \\
\hline \multirow{3}{*}{ MÓDULO 4} & Abandono / Repetência por frequência & - & - & - & - \\
\hline & Aprovados & - & - & - & - \\
\hline & Repetência por nota & - & - & - & - \\
\hline
\end{tabular}

Fonte: Elaboração dos autores com base nos dados disponibilizados pela Seeduc-RJ.

Os anos de 2013 e 2014 revelam um cenário um pouco melhor para os primeiros módulos da EJA. Enquanto a EJA em fases apresentou taxas de abandono e reprovação por frequência muito próximas dos 40\%, em 2011 e 2012, a EJA em módulos registrou índices de $33,2 \%$ e $35,2 \%$, respectivamente, no $1^{\circ}$ semestre de 2013 e $1^{\circ}$ semestre de 2014 . Os demais módulos mantiveram a mesma perspectiva de índices apontada para a EJA em fases semestrais, evidenciando uma forte tendência de os alunos, nessa modalidade de ensino, não continuarem até a conclusão do curso.

Muitos são os motivos que levam o aluno jovem em distorção idade-série ou adulto a persistir e concluir a educação básica, dentre os quais estão o desejo em ascender profissionalmente, ingressar em cursos universitários e, até mesmo, reintegrar-se ao meio social enquanto cidadão ativo e atuante. Contudo, os altos índices de abandono revelam que existem fatores tão quão relevantes que desestimulam e fazem com que ocorra o abandono. Para Pedro Carvalho (2009), mestre em educação pela Universidade Católica de Brasília, existem fatores extra e intraescolares que levam o aluno de EJA ao abandono. O autor, em sua dissertação de mestrado, concluiu que fatores extraescolares, tais como 
[...] necessidade de trabalhar, mudança de residência, distância da escola, dificuldade de conciliar trabalho e escola, pressão de familiares para deixar de estudar e dificuldade em matemática são considerados pelos participantes como os principais motivos/fatores do abandono. Ao encontro de achados de pesquisa e da literatura, os dados revelam, ainda, que os fatores intraescolares como dificuldade de relacionamento com professores, excesso de normas da escola, ausência de conteúdos relevantes para o aluno e as más condições das escolas influenciam, de forma significativa, o abandono escolar. (CARVALHO, 2009, p. 102)

Mais do que garantir o ingresso e a permanência de toda demanda por EJA nos domínios das instituições de ensino, a justiça social somente será consagrada quando essa política pública for capaz de oferecer condições suficientes de conclusão da educação básica com proficiências em Língua Portuguesa e Matemática condizentes com os padrões de qualidade estabelecidos. Nessa perspectiva, as seções seguintes explicitam a análise dos resultados de EJA e a metodologia estatística empregada para esse objetivo.

\section{METODOLOGIA EMPREGADA}

Para analisar os dados decorrentes das avaliações externas com a finalidade de aferir se tais mudanças se convertem em melhoria do desempenho dos alunos e por se tratar de dados quantitativos, as estatísticas descritiva e inferencial assumem nas análises a função de tornar evidentes as premissas que darão subsídios às eventuais conclusões.

As bases de dados que possibilitaram as análises estão disponíveis na Coordenação de Logística das Avaliações Educacionais (Clave) da Superintendência Pedagógica, da Seeduc-RJ. O acesso às informações se deu de forma direta e sem limitações, já que, na época da elaboração do trabalho de dissertação, um dos autores do presente artigo desempenhava a função de coordenador de Análise de Indicadores e Informações Educacionais na Sugen. 
Para uma amostra representativa de alunos concluintes do ensino médio em 2014, modalidade EJA, há proficiências aferidas no início do curso. Após essa primeira análise, em caráter longitudinal, um estudo baseado em desenhos seccionais de avaliação possibilita, por meio das diferentes edições do Saerj, responder em que medida os alunos concluintes da EJA em módulos sobressaíram em relação aos concluintes da fase III, ambas as realidades confrontadas com o ensino médio regular.

Sob essa perspectiva metodológica, o estudo aqui apresentado preocupa-se em avaliar o quanto a EJA em módulos se diferencia da EJA em fases, mais especificamente aos níveis de proficiências aferidos para os concluintes das diferentes propostas para uma mesma modalidade de ensino.

4 A TRI é um conjunto de modelos matemáticos que procuram representar a probabilidade de um indivíduo dar uma certa resposta a um item como função dos parâmetros do item e da habilidade (ou habilidades) do respondente. Essa relação é sempre expressa de tal forma que quanto maior for a habilidade, maior será a probabilidade de acerto do item (ANDRADE; TAVARES; VALLE. 2000, p. 7)

5 A TCT se apropria, como parâmetro de análise de desempenho de dada habilidade, da proporção de acertos e erros para determinado item. Dessa forma, quanto maior for o grau de dificuldade de um item, menor será o percentual de acerto

\section{ANÁLISE DOS RESULTADOS DE PROFICIÊNCIA}

A confiabilidade das análises das proficiências estimadas para os alunos matriculados nos módulos da EJA, medidas obtidas graças à avaliação segundo os parâmetros da Teoria da Resposta ao Item $\left(\mathrm{TRI}^{4}\right)$, se dá pela eficiência dessa técnica de aferição da aprendizagem, em que o aluno é submetido a itens parametrizados estimando sua proficiência na área de conhecimento avaliada. O diferencial entre uma avaliação realizada pela Teoria Clássica dos Testes $\left(\mathrm{TCT}^{5}\right)$ e pela TRI está justamente na potencialidade dessa última em estabelecer parâmetros para um determinado item. Dessa forma, determinam-se "a dificuldade, a discriminação e a probabilidade de resposta correta dada por indivíduos de baixa habilidade" (ANDRADE; TAVARES; VALLE, 2000, p. 9), posicionando os alunos em diferentes níveis de uma escala única para eventuais comparações em diferentes edições de um mesmo sistema de avaliação.

Iniciando a análise dos resultados em Língua Portuguesa, a Tabela 4, sob uma perspectiva longitudinal, apresenta a média, mediana e desvio-padrão das proficiências aferidas em cada uma das avaliações realizadas para a EJA em módulos, assim como o número de alunos avaliados. 
TABELA 4 - Número de alunos avaliados e estatísticas da proficiência em Língua Portuguesa da Nova EJA em cada módulo de ensino nos bimestres de 2013 e 2014

\begin{tabular}{|c|c|c|c|c|c|c|}
\hline & & & \multirow{2}{*}{$\begin{array}{l}\text { NÚMERO DE } \\
\text { ALUNOS }\end{array}$} & \multicolumn{3}{|c|}{ PROFICIÊNCIA EM LÍNGUA PORTUGUESA } \\
\hline & & & & MÉDIA & MEDIANA & DESVIO-PADRÃO \\
\hline \multirow{2}{*}{ Módulo I } & \multirow{2}{*}{$1^{\circ}$ sem. 2013} & $1^{\circ} \mathrm{bim}$. & 18.404 & 222,0 & 222,5 & 45,8 \\
\hline & & $2^{\circ} \mathrm{bim}$. & 15.322 & 230,8 & 232,2 & 43,1 \\
\hline \multirow{2}{*}{ Módulo II } & \multirow{2}{*}{$2^{\circ}$ sem. 2013} & $1^{\circ} \mathrm{bim}$. & & & & \\
\hline & & $2^{\circ} \mathrm{bim}$. & 13.489 & 221,6 & 220,3 & 50,2 \\
\hline \multirow{2}{*}{ Módulo III } & \multirow{2}{*}{$1^{\circ}$ sem. 2014} & $1^{\circ} \mathrm{bim}$. & & & & \\
\hline & & $2^{\circ} \mathrm{bim}$. & 12.620 & 219,7 & 206,5 & 49,6 \\
\hline \multirow{2}{*}{ Módulo IV } & \multirow{2}{*}{$2^{\circ}$ sem. 2014} & $1^{\circ} \mathrm{bim}$. & & & & \\
\hline & & $2^{\circ} \mathrm{bim}$. & 10.773 & 227,3 & 224,7 & 45,4 \\
\hline
\end{tabular}

Fonte: Elaboração dos autores com base nos dados disponibilizados pela Seeduc-RJ.

Nota: Os resultados das avaliações bimestrais nos módulos I, II, III e $1^{\circ}$ bim. do módulo IV referem-se ao Saerjinho (avaliação destinada ao percurso formativo). Os resultados do módulo IV, $2^{\circ}$ bimestre, referem-se ao Saerj (avaliação de conclusão de curso).

Para a pesquisadora em educação da Pontifica Universidade Católica do Rio de Janeiro, Bonamino (2013, p. 40),

Os dados longitudinais permitem, assim, analisar o quan-

to as práticas escolares contribuem para o aprendizado dos alunos durante o ano em que eles frequentaram uma determinada escola e, por essa razão, são considerados um elemento chave nas pesquisas sobre o efeito escola e também sobre a eficácia escolar.

A autora menciona a importância dos dados longitudinais para que determinada escola possa mensurar o efeito que tem causado na aprendizagem de seus alunos. Bonamino (2013, p. 48) ressalta ainda que a "coleta longitudinal de dados possibilita uma maior precisão nas estimativas de mudanças temporais no aprendizado dos alunos do que os estudos seccionais". ${ }^{6}$

Importante destacar que, dentre os alunos avaliados no primeiro módulo, $1^{\circ}$ semestre de 2013 , há desistências ao longo do curso, reprovações nesse módulo e nos seguintes, alunos aprovados para os módulos seguintes e não avaliados na sequência de avaliações por motivos diversos, etc. Há também alunos que ingressaram no curso nos módulos II, III ou IV. Por esse motivo, as médias apresentadas na Tabela 4

6 Para Bonamino (2013, p. 38), numa avaliação com desenho seccional, "o mesmo teste é aplicado a grupos de alunos da série avaliada e estes alunos são diferentes a cada ano de avaliação". 
são de populações distintas, embora haja interseç̧ão considerável de alunos entre elas. Observando a média e mediana das proficiências das diferentes populações de alunos, é possível constatar uma sequência de medidas que não expressam diferenças relevantes entre o desempenho nos diferentes módulos.

Foi possível identificar, dentre os 10.773 alunos avaliados no módulo IV, 6.503 matrículas de alunos avaliados no $1^{\circ}$ bimestre do módulo I. Ao considerar essa intersecção, foram calculadas média e mediana para esse recorte da população e realizado o teste estatístico de Wilcoxon, conforme mostra a Tabela 5 .

TABELA 5 - Estatísticas da proficiência em Língua Portuguesa de alunos avaliados nos módulos I e IV da EJA e os valores do teste de Wilcoxon, referentes à comparação das duas distribuições

\begin{tabular}{|c|c|c|c|c|c|}
\hline & $\begin{array}{c}\text { ALUNOS } \\
\text { AVALIADOS }\end{array}$ & MÉDIA & MEDIANA & DESVIO-PADRÃO & $\begin{array}{l}\text { TESTE DE WILCOXON } \\
\text { (AMOSTRAS PAREADAS); } \\
\text { NÍVEL DE SIGN. = 0,05 }\end{array}$ \\
\hline $\begin{array}{l}\text { Módulo I } \\
\text { (Entrada) }\end{array}$ & 6.503 & 222,2 & 222,7 & 43,5 & \multirow{2}{*}{$\begin{array}{l}\text { Valor }=12133793 \\
\text { P-valor }=0,000\end{array}$} \\
\hline $\begin{array}{l}\text { Módulo IV } \\
\text { (Saída) }\end{array}$ & 6.503 & 226,4 & 224,3 & 44,4 & \\
\hline
\end{tabular}

Fonte: Elaboração dos autores com base nos dados disponibilizados pela Seeduc-RJ.

7 A ideia de que um aluno, avaliado em dois momentos, antes e depois de um curso que possibilitou oportunidade de ganhos de conhecimento, tenha apresentado proficiência consideravelmente menor na segunda avaliação remete à possibilidade de que não tenha se submetido fielmente ao teste.
A análise da Tabela 5 revela uma diferença muito pequena entre as médias $(4,2)$ e entre as medianas $(1,6)$ ao considerar as proficiências dos alunos na conclusão do curso comparando-as à aferição realizada na entrada, não evidenciando um aumento generalizado nas proficiências do subconjunto analisado. Dos 6.503 alunos que compõem a amostra pareada, parte apresentou melhora em suas proficiências, diferença positiva, e outros registraram proficiências menores do que aquelas apuradas na primeira avaliação realizada, diferença negativa. ${ }^{7} \mathrm{O}$ teste de Wilcoxon, com base nos postos associados a essas diferenças positivas e negativas entre as avaliações, permite, ao nível de significância de 5\%, afirmar que o desempenho dos alunos melhorou. No entanto, tal resultado não pode ser encarado como suficiente tendo em vista as estatísticas da proficiência em Língua Portuguesa de entrada e saída da EJA já mencionadas (Tabela 5). 
A proficiência do aluno não é uma medida exata e assume um erro tanto para mais quanto para menos. Esse erro está relacionado ao instrumento de avaliação conforme ensina Klein (2013).

As proficiências estimadas de alunos que respondem a subconjuntos de itens diferentes de um mesmo banco de itens estão na mesma escala e podem ser comparadas. [...] a proficiência de um aluno é a mesma não dependendo do particular subconjunto de itens utilizado, mas suas estimativas variam por causa do erro de medida e algumas estimativas serão melhores que outras por causa do uso de itens mais ou menos apropriados nos testes para ele. (KLEIN, 2013, p. 11)

O Saerj considera amplitude de 50 e 75 pontos, em Língua Portuguesa, entre suas diferentes classes de desempenho. O diagrama de dispersão apresentado a seguir (Gráfico 1) adota a amplitude definida pelo Saerj para verificar se os alunos analisados mostraram algum progresso decorrente do ensino médio na modalidade EJA. Portanto, consideram-se as proficiências de entrada e de conclusão da amostra de 6.503 alunos avaliados em Língua Portuguesa, possibilitando uma perspectiva de análise cartesiana.

GRÁFICO 1 - Dispersão entre proficiência em Língua Portuguesa estimada no início do módulo I (primeiro semestre de 2013) e proficiência estimada na conclusão do módulo IV (segundo semestre de 2014) para alunos matriculados no ensino médio modalidade EJA

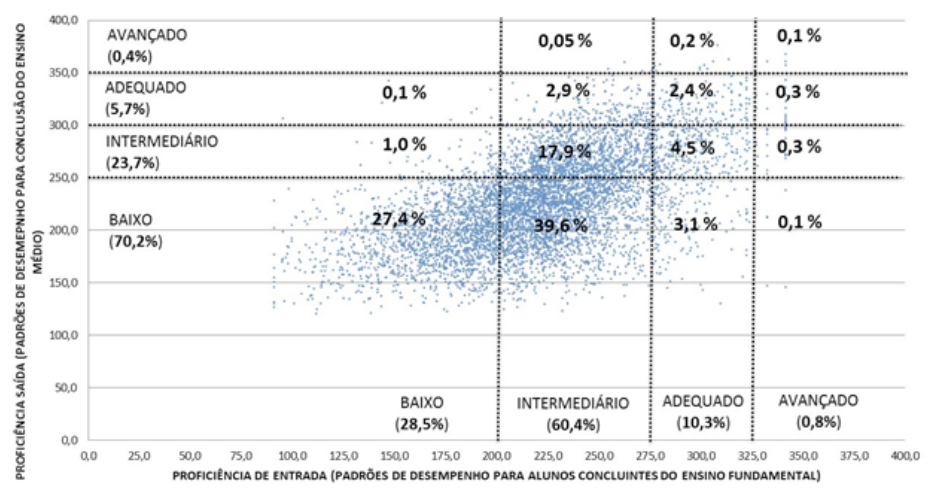

Fonte: Elaboração dos autores com base nos dados disponibilizados pela Seeduc-RJ. 
O Gráfico 1 mostra que 60,4\% dos alunos obtiveram desempenho intermediário no primeiro semestre de 2013. Esses alunos, na conclusão do curso, se redistribuíram nos diferentes padrões de desempenho do ensino médio da seguinte forma: $39,6 \%$ se posicionaram no padrão baixo; $17,9 \%$ permaneceram com desempenho intermediário; e os demais 3\% elevaram suas proficiências ao padrão de desempenho adequado ou avançado. Verifica-se um considerável aumento de alunos no desempenho baixo na conclusão do curso.

Assim como para Língua Portuguesa, a média, mediana e desvio-padrão das proficiências estimadas para alunos em cada edição do Saerjinho e Saerj são apresentados para Matemática na Tabela 6. Os dados sugerem uma sequência estabelecida pela média e mediana que não indicam ganhos significativos à população.

TABELA 6 - Número de alunos e estatísticas da proficiência em Matemática da Nova EJA em cada módulo de ensino nos bimestres de 2013 e 2014

\begin{tabular}{|c|c|c|c|c|c|c|}
\hline & & & \multirow{2}{*}{$\begin{array}{l}\text { NÚMERO DE } \\
\text { ALUNOS }\end{array}$} & \multicolumn{3}{|c|}{ PROFICIÊNCIA EM MATEMÁTICA } \\
\hline & & & & MÉDIA & MEDIANA & DESVIO-PADRÃO \\
\hline \multirow{2}{*}{ Módulo I } & \multirow{2}{*}{$1^{\circ} \mathrm{sem} .2013$} & $1^{\circ} \mathrm{bim}$. & 18.409 & 229,2 & 234,1 & 51,0 \\
\hline & & $2^{\circ} \mathrm{bim}$. & 15.323 & 232,5 & 229,3 & 43,7 \\
\hline \multirow{2}{*}{ Módulo II } & \multirow{2}{*}{$2^{\circ}$ sem. 2013} & $1^{\circ} \mathrm{bim}$. & & & & \\
\hline & & $2^{\circ} \mathrm{bim}$. & 13.489 & 234,9 & 234,7 & 57,7 \\
\hline \multirow{2}{*}{ Módulo III } & \multirow{2}{*}{$1^{\circ}$ sem. 2014} & $1^{\circ} \mathrm{bim}$. & & & & \\
\hline & & $2^{\circ} \mathrm{bim}$ & 12.616 & 231,2 & 227,2 & 29,9 \\
\hline \multirow{2}{*}{ Módulo IV } & \multirow{2}{*}{$2^{\circ}$ sem. 2014} & $1^{\circ} \mathrm{bim}$ & & & & \\
\hline & & $2^{\circ} \mathrm{bim}$. & 10.769 & 229,6 & 226,6 & 38,8 \\
\hline
\end{tabular}

Fonte: Elaboração dos autores com base nos dados disponibilizados pela Seeduc-RJ.

Nota: Os resultados das avaliações bimestrais nos módulos I, II, III e $1^{\circ}$ bim. do módulo IV referem-se ao Saerjinho (avaliação destinada ao percurso formativo). Os resultados do módulo IV, $2^{\circ}$ bimestre, referem-se ao Saerj (avaliação de conclusão de curso).

Voltando a análise somente para o conjunto de alunos concluintes que foram avaliados também na entrada do primeiro módulo, a média assume uma variação negativa igual a -3,4 e a mediana, -10,5. O teste de Wilcoxon para amostras pareadas, Tabela 7, revela, ao nível de significância de 5\%, diferença significante entre as distribuições das proficiências, no sentido indicado pela variação negativa da média e mediana. 
TABELA 7 - Estatísticas da proficiência em Matemática de alunos avaliados nos módulos I e IV da EJA e os valores do teste de Wilcoxon, referentes à comparação das duas distribuições

\begin{tabular}{|c|c|c|c|c|c|}
\hline & $\begin{array}{c}\text { ALUNOS } \\
\text { AVALIADOS }\end{array}$ & MÉDIA & MEDIANA & DESVIO-PADRÃO & $\begin{array}{l}\text { TESTE DE WILCOXON } \\
\text { (AMOSTRAS PAREADAS); } \\
\text { NÍVEL DE SIGN. = 0,05 }\end{array}$ \\
\hline $\begin{array}{l}\text { Módulo I } \\
\text { (Entrada) }\end{array}$ & 6.503 & 231,2 & 235,5 & 50,1 & \multirow{2}{*}{$\begin{array}{l}\text { Valor }=9598223,5 \\
\text { P-valor }=0,000\end{array}$} \\
\hline $\begin{array}{l}\text { Módulo IV } \\
\text { (Saída) }\end{array}$ & 6.503 & 227,8 & 225,0 & 37,6 & \\
\hline
\end{tabular}

Fonte: Elaboração dos autores com base nos dados disponibilizados pela Seeduc-RJ.

Conceber a hipótese de piora nos resultados nega o princípio de que a proficiência tende a aumentar no decorrer de um percurso formativo. Seria, no mínimo, plausível admitir a ideia de que houve uma estagnação dos resultados, na medida em que a diferença, embora relevante conforme evidências apontadas pelo teste de Wilcoxon, não é suficiente para apontar retrocessos. Nesse caso, o resultado das duas avaliações pode ter sofrido influência de variáveis não observáveis, tais como dedicação do aluno ao submeter-se ao instrumento de avaliação e especificidades dos itens utilizados nos instrumentos.

O resultado obtido em relação ao desempenho em Matemática para os alunos avaliados na situação de entrada e saída da EJA em módulos é reafirmado pela apresentação do diagrama de dispersão (Gráfico 2), que mostra um expressivo contingente de alunos que se mantiveram com desempenho baixo tanto no início do curso quanto na conclusão, 40,6\% da amostra. 
GRÁFICO 2 - Dispersão entre proficiência em Matemática estimada no início do módulo I (primeiro semestre de 2013) e proficiência estimada na conclusão do módulo IV (segundo semestre de 2014) para alunos matriculados no ensino médio modalidade EJA

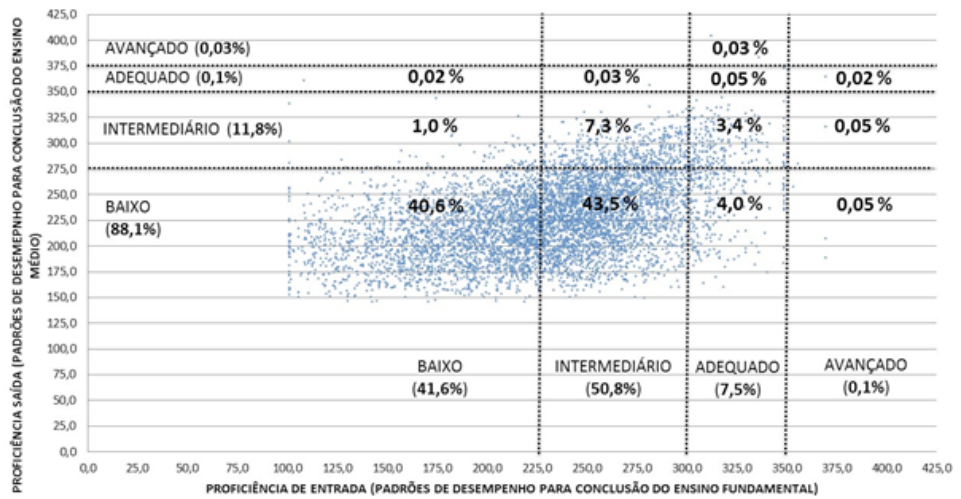

Fonte: Elaboração dos autores com base nos dados disponibilizados pela Seeduc-RJ.

Na primeira aferição mais de 50\% dos alunos da amostra apresentavam-se no desempenho intermediário ou superior. Com a conclusão do ensino médio, a soma do percentual de alunos nesses padrões foi de $12 \%$. Com isso, $88,1 \%$ dos alunos da amostra concluíram o ensino médio da EJA com desempenho insuficiente em Matemática para essa última etapa da educação básica.

Por fim, tendo analisado os resultados de TRI na entrada ( $1^{\circ}$ Saerjinho) e saída (Saerj 2014), é feita, a seguir, uma descrição das médias populacionais no Saerj de 2011 a 2014. Dessa forma, será possível entender como evoluíram essas medidas tanto para o ensino médio regular quanto para EJA, considerando todas as diferentes populações avaliadas de alunos concluintes.

Os resultados do Saerj de 2014 são responsáveis em apontar se o novo desenho de EJA, em seu primeiro ciclo, foi capaz de elevar o nível de proficiência em Língua Portuguesa e Matemática dos alunos a patamares maiores do que os observados para os alunos egressos da EJA organizada em três fases semestrais em 2013 e anos anteriores. Para começar a entender essa problemática, o Gráfico 3 mostra a média das proficiências de todos alunos avaliados nos últimos anos para o ensino médio regular e modalidade EJA, inclusive os resultados de 2014. Esse gráfico traz a média das 
proficiências dos primeiros concluintes da EJA em módulos semestrais.

GRÁFICO 3 - Proficiências médias para Língua Portuguesa e Matemática na rede estadual de ensino do Rio de Janeiro em 2011, 2012, 2013 e 2014

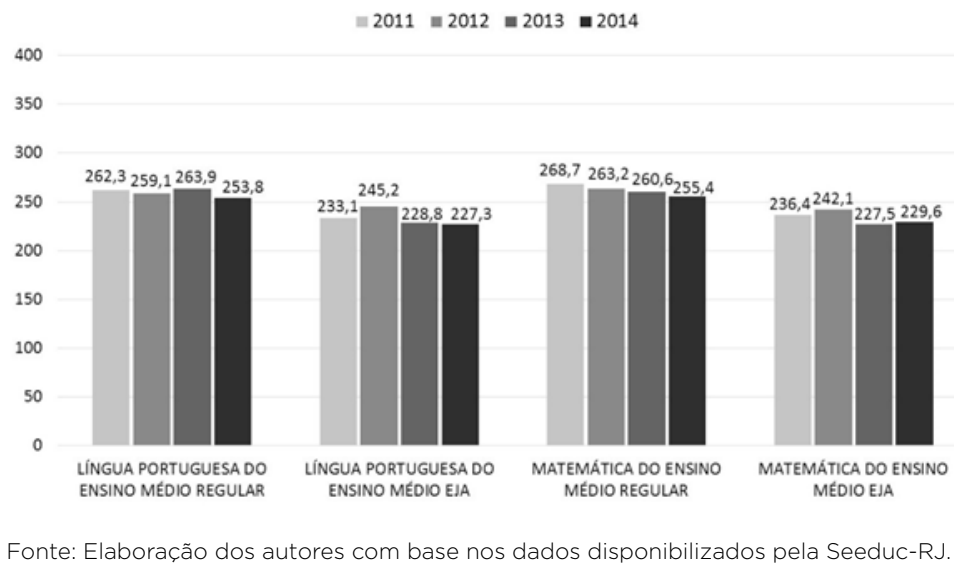

Apesar da diferença em relação aos resultados de 2013, as médias de Língua Portuguesa e Matemática em 2014 não sofreram alterações consideráveis ao ponto de superar as medidas obtidas dos resultados dos alunos concluintes da fase III.

Outra perspectiva de análise (Gráfico 4) leva em consideração o fato de a EJA ser ofertada, em número expressivo de turmas, no período noturno. Por esse motivo, é válido estabelecer um comparativo entre proficiência média dos alunos do ensino médio regular noturno e alunos da EJA para fazer uma análise dos resultados dessas duas realidades nos últimos anos e verificar uma possível aproximação dessas medidas. 
GRÁFICO 4 - Proficiências médias para Língua Portuguesa e Matemática na rede estadual de ensino do Rio de Janeiro em 2011, 2012, 2013 e 2014

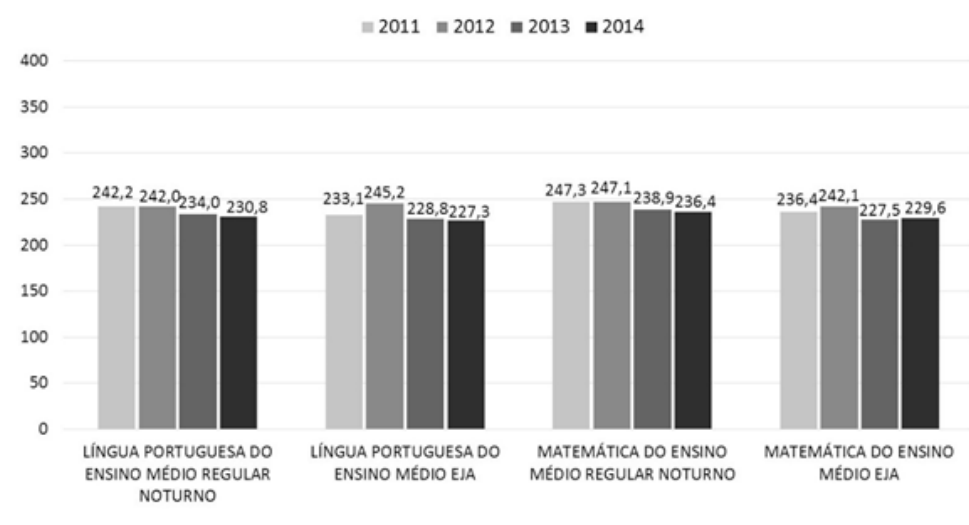

Fonte: Elaboração dos autores com base nos dados disponibilizados pela Seeduc-RJ.

O ensino médio regular noturno, comparado à EJA, apresentou medidas melhores, exceto em Língua Portuguesa em 2012, que ficou um pouco abaixo da média observada para EJA. No entanto, considerando 2011, 2013 e 2014, há uma notoriedade dos resultados do ensino médio regular noturno em relação aos da EJA.

Quanto aos resultados de 2014, foi aplicado o teste de Wilcoxon-Mann-Whitney para verificar, com um nível de significância de $5 \%(\alpha=0,05)$, se uma população tende a apresentar valores maiores do que a outra, ou seja, se há notoriedade para os resultados do ensino médio regular noturno. A Tabela 8 mostra as estatísticas desse teste.

TABELA 8 - Teste de Wilcoxon-Mann-Whitney para diferenças entre as distribuições de proficiências entre ensino médio regular noturno e ensino médio EJA, em 2014

\begin{tabular}{|c|c|c|c|c|c|}
\hline & \multicolumn{2}{|c|}{ MÉDIA DAS PROFICIÊNCIAS } & \multirow{2}{*}{ DIFERENÇA } & \multicolumn{2}{|c|}{$\begin{array}{l}\text { TESTE DE WILCOXON-MANN-WHITNEY; } \\
\text { NÍVEL DE SIGN. = 0,05 }\end{array}$} \\
\hline & $\begin{array}{l}\text { EM REGULAR } \\
\text { NOTURNO }\end{array}$ & EM DA EJA & & VALOR & P-VALOR \\
\hline Língua Portuguesa & 230,8 & 227,3 & 3,5 & 128476065,5 & 0,00 \\
\hline Matemática & 236,4 & 229,6 & 6,8 & 122405384,5 & 0,00 \\
\hline
\end{tabular}

Fonte: Elaboração dos autores com base nos dados disponibilizados pela Seeduc-RJ. 
Embora a diferença para as médias estimadas dos resultados de Matemática seja um pouco maior do que a de Língua Portuguesa, em ambos os casos, há evidências para aceitar a hipótese de que existe uma real diferença entre as médias do ensino médio regular noturno e EJA.

As médias de 2013 e 2014 (Tabela 9), que mostram medidas calculadas em função de resultados de alunos da EJA em fases e EJA em módulos, respectivamente, sugerem uma pequena diferença positiva para Matemática e um discreto recuo para Língua Portuguesa, no entanto, aparentemente, ambos os casos são insuficientes para inferir movimento de melhora ou piora decorrente das mudanças nessa modalidade de ensino. O teste de Wilcoxon-Mann-Whitney foi aplicado para verificar se essas médias retratam realidades similares para os resultados da fase III e módulo IV ao nível de significância de $5 \%(\alpha=0,05)$ sob a hipótese de que os desempenhos médios dos alunos, em ambas as edições, apresentam distribuições equivalentes.

TABELA 9 - Teste de Wilcoxon-Mann-Whitney para diferenças entre as distribuições de proficiências entre resultados da fase III em 2013 e resultados do módulo IV em 2014

\begin{tabular}{|c|c|c|c|c|c|}
\hline \multirow{2}{*}{$\begin{array}{l}\text { ENSINO MÉDIO } \\
\text { DA EJA }\end{array}$} & \multicolumn{2}{|c|}{$\begin{array}{l}\text { MÉDIA DAS } \\
\text { PROFICIÊNCIAS }\end{array}$} & \multirow{2}{*}{ DIFERENÇA } & \multicolumn{2}{|c|}{$\begin{array}{l}\text { TESTE DE WILCOXON-MANN-WHITNEY; } \\
\text { NÍVEL DE SIGN. = 0,05 }\end{array}$} \\
\hline & $\begin{array}{l}\text { MÓDULO IV } \\
(2014)\end{array}$ & $\begin{array}{l}\text { FASE III } \\
(2013)\end{array}$ & & VALOR & P-VALOR \\
\hline Língua Portuguesa & 227,3 & 228,8 & $-1,5$ & 60899379,5 & 0,026 \\
\hline Matemática & 229,6 & 227,5 & 2,1 & 64189461,0 & 0,000 \\
\hline
\end{tabular}

Fonte: Elaboração dos autores com base nos dados disponibilizados pela Seeduc-RJ.

$\mathrm{O}$ teste revela uma probabilidade pequena, P-valor, em equivocar-se ao rejeitar a hipótese de que os desempenhos médios dos alunos são equivalentes, visto que pela aplicação do teste há evidências de diferença entre as distribuições estudadas, no entanto, não é o bastante para impactar em ganhos para Matemática ou prejuízos para Língua Portuguesa. O fato de as duas populações de alunos serem distintas impede comparações conclusivas acerca de seus desempenhos.

Partindo-se do pressuposto de que a EJA é uma modalidade voltada para um perfil de alunos mais velhos, ou seja, que não tiveram oportunidade de escolarizar-se em idade 
apropriada, foram estabelecidas classes de idade com amplitude dez anos e calculada a média das proficiências para os grupos que pertencem a cada uma delas. A Tabela 10 permite uma análise dessas médias para alunos do noturno das duas modalidades, visto que é o turno de maior prevalência da Educação de Jovens e Adultos. Para isso, foram consideradas unidades escolares com oferta de ambas as modalidades, regular e EJA, no noturno. Escolas que ofertam somente o ensino regular ou somente a EJA no turno da noite não foram incluídas.

TABELA 10 - Proficiência média dos alunos que concluíram o ensino médio em 2014 em escolas com oferta de ambas as modalidades, ensino médio regular e EJA, no noturno por faixa etária

\begin{tabular}{|c|c|c|c|c|c|c|c|c|c|c|}
\hline \multirow{3}{*}{ FAIXA ETÁRIA } & \multicolumn{4}{|c|}{ EM - EJA NOTURNO } & \multicolumn{4}{|c|}{ EM - REGULAR NOTURNO } & \multirow{2}{*}{\multicolumn{2}{|c|}{$\begin{array}{l}\text { DIFERENÇA } \\
\text { DE MÉDIAS } \\
\text { (EJA;REG) }\end{array}$}} \\
\hline & \multirow{2}{*}{$\mathrm{N}$} & \multirow{2}{*}{$\%$} & \multicolumn{2}{|c|}{$\begin{array}{c}\text { PROFICIÊNCIA } \\
\text { MÉDIA }\end{array}$} & \multirow{2}{*}{$N$} & \multirow{2}{*}{$\%$} & \multicolumn{2}{|c|}{$\begin{array}{c}\text { PROFICIÊNCIA } \\
\text { MÉDIA }\end{array}$} & & \\
\hline & & & LP & MAT & & & LP & MAT & LP & MAT \\
\hline Até 20 & 803 & $16,0 \%$ & 224,4 & 230,0 & 6457 & $76,1 \%$ & 230,5 & 238,4 & $-6,1$ & $-8,4$ \\
\hline $20-/ 30$ & 1616 & $32,3 \%$ & 227,6 & 231,9 & 1206 & $14,2 \%$ & 218,7 & 225,0 & 8,9 & 6,9 \\
\hline $30-/ 40$ & 1116 & $22,3 \%$ & 232,7 & 230,3 & 352 & $4,1 \%$ & 228,6 & 222,4 & 4,1 & 7,9 \\
\hline $40-/ 50$ & 939 & $18,8 \%$ & 229,3 & 228,6 & 274 & $3,2 \%$ & 225,5 & 224,7 & 3,8 & 3,9 \\
\hline $50-/ 60$ & 422 & $8,4 \%$ & 223,1 & 225,4 & 158 & $1,9 \%$ & 221,1 & 221,0 & 2,0 & 4,4 \\
\hline $60-/ 70$ & 103 & $2,1 \%$ & 218,4 & 217,4 & 36 & $0,4 \%$ & 207,2 & 204,0 & 11,2 & 13,4 \\
\hline Acima de 70 & 6 & $0,1 \%$ & 191,1 & 191,1 & 6 & $0,1 \%$ & 177,0 & 199,6 & 14,1 & $-8,5$ \\
\hline $\begin{array}{l}\text { Subtotal: } \\
\text { Acima de } 20\end{array}$ & 4202 & $84,0 \%$ & 228,7 & 229,7 & 2032 & $23,9 \%$ & 221,2 & 223,8 & 7,5 & 5,9 \\
\hline Total & 5005 & $100,0 \%$ & 228,0 & 229,7 & 8489 & $100,0 \%$ & 228,3 & 234,9 & $-0,3$ & $-5,2$ \\
\hline
\end{tabular}

Fonte: Elaboração dos autores com base nos dados disponibilizados pela Seeduc-RJ.

Para esse subconjunto, alunos do ensino regular com até 20 anos de idade sobressaem em relação aos demais. A média geral para Língua Portuguesa da EJA apresenta medida muito próxima do ensino regular. $\mathrm{O}$ ensino regular noturno geralmente registra desempenhos inferiores aos do diurno, contudo, ao desconsiderar os alunos da faixa etária de até 20 anos para o subconjunto analisado, a média da EJA supera, com uma diferença considerável, a do ensino regular noturno, nas duas disciplinas analisadas. É o que pode ser verificado na penúltima linha da Tabela 10 . 
Essa análise, voltada somente a alunos maiores de 20 anos e concluintes do ensino médio em unidades escolares com oferta das diferentes modalidades de ensino, regular e EJA, no noturno, traz indícios de que os alunos concluintes do ensino regular noturno não demonstraram proficiência no mesmo nível dos concluintes do quarto módulo do ensino médio da EJA. Esses dados mostram que a EJA cumpre com o objetivo de oferecer maiores garantias de aprendizagem ao perfil de alunos mais velhos. No entanto, somente uma avaliação de impacto, com grupos estatisticamente comparáveis, clones estatísticos, sendo um grupo controle, matriculado no ensino regular, e um grupo tratamento, matriculado na EJA, traria resultados conclusivos acerca dessa hipótese.

\section{CONSIDERAÇÕES FINAIS}

Num momento da história do Brasil em que a conquista do direito social à educação se intensificou pelo acesso à escola cada vez mais universalizado, o poder público e a sociedade em geral almejam ideais de qualidade para esse setor na medida em que a escolarização se tornou um dos pré-requisitos para que haja o reconhecimento do status de uma nação desenvolvida, por parte dos órgãos internacionais, em vez de uma nação em desenvolvimento.

Na última década, a EJA passou a ser encarada não só como uma modalidade voltada para a alfabetização, mas também como uma alternativa àqueles que não puderam frequentar a escola na idade oportuna para concluir a educação básica. As dificuldades para que os adultos frequentem a escola, na maioria dos casos no horário noturno, são muitas. Conciliar estudo, trabalho e responsabilidades para com a família pode tornar-se um obstáculo que muitos não conseguem transpor. No entanto, a necessidade de buscar novas oportunidades, seja adentrar um curso superior, seja buscar melhores nichos no mercado de trabalho, motiva muitos a retornar à escola, optando por concluir o ensino médio por meio de uma modalidade de ensino que lhes possibilite a obtenção do certificado em menos tempo. Além das limitações 
causadas pelo cansaço físico e peso da responsabilidade da vida adulta, o estudante-alvo da EJA enfrenta uma série de obstáculos relacionados ao processo ensino-aprendizagem, visto que o tempo longe da escola o fez distanciar-se de uma série de conhecimentos e habilidades, pré-requisitos para o curso do ensino médio.

Toda essa realidade exige do estudante jovem ou adulto um esforço muito grande para concluir o ensino médio e alcançar níveis de proficiência condizentes a essa etapa da educação básica. A EJA, embora criada para atender a uma demanda específica, não deve certificar o aluno colocando-o num patamar de condições de acesso e competitividade inferior aos concluintes do curso regular. Até 2013, o aluno matriculado no curso de EJA concluía o ensino médio em dezoito meses e, a partir desse mesmo ano, com a Nova EJA, os quatro módulos semestrais passaram a oportunizar um tempo maior para a aprendizagem e condições mais favoráveis de tempo de estudos. De certa forma, o aumento do tempo de dedicação às aulas e contato com o professor, a disponibilidade de material didático e a formação metodológica específica aos docentes desencadearam uma expectativa de melhora em relação aos resultados de aprendizagem.

Mesmo com essas mudanças, o primeiro ciclo da EJA em módulos, iniciado no primeiro semestre de 2013 com matrículas de alunos no módulo I e findado no segundo semestre de 2014 com a conclusão de grande parte desses mesmos alunos no módulo IV, não conseguiu, conforme as análises desenvolvidas com resultados do módulo IV no Saerj, apresentar diferença positiva relevante em relação aos resultados de concluintes da EJA em três fases semestrais.

Éde extrema importância que os resultados, proficiências em Língua Portuguesa e Matemática dos alunos concluintes do novo desenho de EJA, continuem sendo aferidos e monitorados, semestre a semestre, para avaliar se essa proposta de oferta de ensino médio tem apresentado influência positiva nos níveis de conhecimento dos estudantes. Embora o primeiro ciclo da EJA em módulos não tenha apresentado diferença significativa na proficiência média da população avaliada, em relação à EJA em fases, é importante investigar 


\section{se os demais ciclos refletiram ou proporcionarão algum tipo de melhora em função de ações que possam prevenir um cenário de estagnação que não se espera para essa proposta.}

\section{REFERÊNCIAS}

ANDRADE, Dalton Francisco; TAVARES, Heliton Ribeiro; VALLE, Raquel da Cunha. Teoria da Resposta ao Item: conceitos e aplicações. Sinape, 2000. Disponível em: <http://homes.ufam.edu.br/jcardoso/LivroTRI.pdf>. Acesso em: 11 maio 2017.

BONAMINO, Alicia Maria Catalano de. Estudos longitudinais e pesquisa na educação básica. Brasília, DF: Linhas Críticas, 2013. Disponível em: <http://periodicos.unb.br/index.php/linhascriticas/article/view/8918>. Acesso em: 10 set. 2016.

BRASIL. Presidência da República. Casa Civil. Constituição da República Federativa do Brasil. Brasília, DF, 1988.

BRASIL. Presidência da República. Casa Civil. Lei n. 9.394, de 20 de dezembro de 1996. Estabelece as Diretrizes e Bases da Educação Nacional. Brasília, DF, 1996. Disponível em: <http://www.planalto.gov.br/ccivil_03/leis/19394.htm>. Acesso em: 10 set. 2016.

BRASIL. Ministério da Educação. Conselho Nacional de Educação. Parecer CNE/CEB n. 11/2000. Define as Diretrizes Curriculares Nacionais para Educação de Jovens e Adultos. Brasília, DF, 2000. Disponível em: <http:// portal.mec.gov.br/secad/arquivos/pdf/eja/legislacao/parecer_11_2000.pdf>. Acesso em: 10 set. 2016.

BROOKE, Nigel. Marcos históricos na reforma da educação. Belo Horizonte: Fino Traço, 2012.

CARVALHO, Pedro Leite. Afastamento por abandono na educação de jovens e adultos: fatores relevantes. 2009. 114 f. Dissertação (Mestrado em Educação) Universidade Católica de Brasília, Brasília, DF, 2009. Disponível em: <https:/ bdtd.ucb.br:8443/jspui/bitstream/123456789/918/1/Texto\%20completo\%20 \%20Pedro\%20Carvalho\%202009.pdf>. Acesso em: 29 nov. 2017.

HOTTZ, Ângelo Damaceno. Educação de Jovens e Adultos: uma análise voltada à interpretação dos resultados do ensino médio no sistema de avaliação da educação do estado do Rio de Janeiro (Saerj) em 2014. 2015. 163 f. Dissertação (Mestrado em Gestão e Avaliação da Educação Pública) - Universidade Federal de Juiz de Fora, Juiz de Fora, 2014. Disponível em: < http://www.mestrado. caeduff.net/wp-content/uploads/2015/10/\%C3\%82NGELO-DAMACENO-HOTTZ. pdf>. Acesso em: 10 set. 2016.

KLEIN, Ruben. Alguns aspectos da Teoria de Resposta ao Item relativos à estimação das proficiências. Ensaio: Avaliação e Políticas Públicas em Educação, Rio de Janeiro, v. 21, n. 78, p. 35-56, jan./mar. 2013. Disponível em: <http://www.scielo.br/pdf/ensaio/2013nahead/aop_0213.pdf>.

Acesso em: 10 set. 2016. 
PAIVA, Jane. Educação de Jovens e Adultos: direito, concepções e sentidos. 2005. 480 f. Tese (Doutorado em Educação) - Faculdade de Educação, Universidade Federal Fluminense, Niterói, 2005.

RIO DE JANEIRO (Estado). Conselho Estadual de Educação. Câmara de Educação Básica. Deliberação CEE n. 285/2003, de 26 de agosto de 2003. Altera normas para o funcionamento de cursos destinados à Educação para Jovens e Adultos, revoga os artigos $7^{\circ}, 8^{\circ}, 9^{\circ}$ e $12^{\circ}$ da Deliberação CEE n. 259/2000, e dá outras providências. Rio de Janeiro, 26 de agosto de 2003. Disponível em: <www.cee. rj.gov.br/coletanea/d285.pdf>. Acesso em: 10 set. 2016.

RIO DE JANEIRO (Estado). Parecer CEE n. 091 de 26 de junho de 2012. Aprova proposta da Secretaria de Estado de Educação - SEEDUC para ministrar Curso de Educação para Jovens e Adultos - Nova EJA. Diário Oficial do Estado do Rio de Janeiro, Rio de Janeiro, 17 de setembro de 2012.

VENTURA, Jaqueline. A diminuição das matrículas na EJA no Rio de Janeiro - cenários e enfrentamentos a partir do Fórum EJA/RJ. Revista Cátedra Digital, Rio de Janeiro, n. 3, 2016. Disponível em: < http://revista.catedra.puc-rio. br/index.php/diminuicao-das-matriculas-na-eja-no-rio-de-janeiro-cenarios-eenfrentamentos-partir-do-forum-ejarj/>. Acesso em: 28 nov. 2017.

Recebido em: 12 MAIO 2017

Aprovado para publicação em: 16 FEVEREIRO 2018 
